\title{
Pathophysiology and diagnosis of cancer drug induced cardiomyopathy
}

\author{
Christian Zuppinger - Francesco Timolati • \\ Thomas M. Suter
}

Published online: 26 April 2007

(C) Humana Press Inc. 2007

\begin{abstract}
The clinical manifestations of anti-cancer drug associated cardiac side effects are diverse and can range from acutely induced cardiac arrhythmias to Q-T interval prolongation, changes in coronary vasomotion with consecutive myocardial ischemia, myocarditis, pericarditis, severe contractile dysfunction, and potentially fatal heart failure. The pathophysiology of these adverse effects is similarly heterogeneous and the identification of potential mechanisms is frequently difficult since the majority of cancer patients is not only treated with a multitude of cancer drugs but might also be exposed to potentially cardiotoxic radiation therapy. Some of the targets inhibited by new anti-cancer drugs also appear to be important for the maintenance of cellular homeostasis of normal tissue, in particular during exposure to cytotoxic chemotherapy. If acute chemotherapy-induced myocardial damage is only moderate, the process of myocardial remodeling can lead to progressive myocardial dysfunction over years and eventually induce myocardial dysfunction and heart failure. The tools for diagnosing anti-cancer drug associated cardiotoxicity and monitoring patients during chemotherapy include invasive and noninvasive techniques as well as laboratory investigations and are mostly only validated for anthracycline-induced cardiotoxicity and more recently for trastuzumab-associated cardiac dysfunction.
\end{abstract}

Keywords Cardiotoxicity - Cancer - Anthracycline . Trastuzumab · Diagnosis · Cardiomyocytes

C. Zuppinger · F. Timolati - Thomas M.Suter $(\bowtie)$

Swiss Cardiovascular Center Bern, Cardiology, Inselspital, University Hospital, 3010 Bern, Switzerland

e-mail: thomas.suter@insel.ch

\section{Introduction}

The clinical manifestations of anti-cancer drug associated cardiac side effects are diverse and can range from acutely induced cardiac arrhythmias to Q-T interval prolongation, changes in coronary vasomotion with consecutive myocardial ischemia, myocarditis, pericarditis, severe contractile dysfunction, and potentially fatal heart failure. The pathophysiology of these adverse effects is similarly heterogeneous and the identification of potential mechanisms is frequently difficult since the majority of cancer patients is not only treated with a multitude of cancer drugs but might also be exposed to potentially cardiotoxic radiation therapy. The long-term prognosis of cancer survivors not only depends on the efficacy of the anti-cancer therapy, but is also influenced by treatment-associated, irreversible side effects. The cardiovascular side effects are important since they can lead to chronic and progressive cardiac disease and therefore might significantly impair long-term prognosis of cancer survivors. In particularly, the chemotherapy-associated cardiomyopathy and heart failure have a bad prognosis and should be avoided whenever possible.

The pathophysiological mechanisms leading to chemotherapy-induced cardiomyopathy are mainly associated with myocardial cell loss, either due to apoptosis or necrosis. This cell loss is the net result of the direct cardiotoxic effects of the cancer therapy on one side and myocardial endogenous cardioprotective mechanisms such as activation of antioxidative capacity, growth factors, nitric oxide, gp130 and the neuregulin/ErbB signaling system on the other side. If the extent of myocardial cell loss is significant, contractile dysfunction might appear months after chemotherapy. Alternatively, if acute chemotherapyinduced myocardial damage is only moderate, a process called myocardial remodeling can take years leading to 
progressive myocardial dysfunction and eventually heart failure. However, it is also important to note, that acute cancer drug-associated cardiac dysfunction can be induced by structural changes of the myocardial contractile proteins which are reversible and therefore may not lead to longterm cardiac dysfunction [1].

\section{Clinical manifestation of cancer drug associated cardiotoxicity}

One of the clinically most important cancer drug induced cardiac side effects is anthracycline-associated cardiomyopathy. Anthracyclines were discovered in the 1960s and remain one of the mainstays of modern cancer therapy. Solid tumors such as breast cancer, sarcoma, ovarian and bronchogenic carcinoma as well as lymphoma, and certain forms of leukemia are some of the malignancies treated with anthracyclines. The anti-cancer mechanisms of anthracyclines are not completely understood but likely include inhibition of DNA replication by intercalating between the base pairs and modifications of cellular proteins and organelles by induction of free oxygen radicals. Free radical production also appears to be a major mechanism of anthracycline-associated cardiac dysfunction.

Manifestation of anthracycline-associated cardiac toxicity (Table 1) can be diverse. Early cardiac side effects occur within hours to days following therapy and typically include arrhythmias, ECG changes, and infrequently pericarditis and myocarditis. These manifestations usually respond promptly to the cessation of anthracycline infusion and rarely preclude further continuation of anthracycline treatment. Chronic or late anthracycline cardiotoxicity

Table 1 Clinical manifestation of anthracycline-associate cardiotoxicity

\begin{tabular}{|c|c|}
\hline \multicolumn{2}{|c|}{ Acute anthracycline cardiotoxicity } \\
\hline Onset & Hours-days following therapy \\
\hline Manifestation & $\begin{array}{l}\text { ECG changes } \\
\text { Arrhythmias } \\
\text { Pericarditis (infrequent) } \\
\text { Myocarditis (infrequent) }\end{array}$ \\
\hline Importance & $\begin{array}{l}\text { Usually resolves after cessation of infusion } \\
\text { Rarely precludes further treatment } \\
\text { with anthracyclines }\end{array}$ \\
\hline \multicolumn{2}{|c|}{ Sub-acute / chronic cardiotoxicity } \\
\hline \multicolumn{2}{|l|}{ Onset } \\
\hline Subacute & Months following therapy \\
\hline Chronic & Months-years following therapy \\
\hline Manifestation & Contractile dysfunction and heart failure \\
\hline Importance & $\begin{array}{l}\text { Progressive disease requiring therapy } \\
\text { Prognosis worse than other forms } \\
\text { of cardio-myopathies }\end{array}$ \\
\hline
\end{tabular}

typically manifests months or years after chemotherapy and most frequently leads to cardiomyopathy with a bad prognosis for the affected patients. Indeed, survival of patients with anthracycline-associated heart failure is worse than that of patients with ischemic or dilated cardiomyopathy [2]. Furthermore, loss of myocardium, regardless of the etiology, usually induces myocardial remodeling, a relentless process eventually leading to endstage heart failure. Evidence from patients with ischemic and dilated cardiomyopathies suggests that this remodeling is, among others, mediated by the activation of the reninangiotensin-aldosteron (RAA) and adrenergic system and that treatment with ACE-inhibitors, angiotensin receptor blockers (ARB), aldosterone antagonists, and beta blockers can slow the progression of disease [3]. It is therefore, reasonable to suggest treating patients with anthracyclineassociated systolic dysfunction or heart failure with RAA inhibitors and beta-blockers, despite limited data on their effectiveness in these patients.

There are several known risk factors for anthracycline (or more specifically doxorubicin) - associated cardiotoxicity (Table 2). The cumulative dose appears to be the most important one and recent data suggest that the risk of anthracycline-associated heart failure is higher than initially estimated [4]. The incidence of doxorubicin-induced heart failure increases linearly and reaches approximately $5 \%$ at a cumulative dose of $400-450 \mathrm{mg} / \mathrm{m}^{2}$. At higher cumulative doses the risk increases exponentially and children, women, and older ( $>65$ years) patients appear to be more sensitive [5]. Other risk factors for anthracyclineinduced cardiotoxicity include combination cancer therapy, prior or concomitant mediastinal radiotherapy, previous cardiac disease, and hypertension [6].

Several non-anthracycline based cancer drugs have also been associated with significant cardiac side effects. An overview of the most important cancer drugs is shown in Table 3.

\section{Pathophysiology of anthracycline-induced cardiotoxicity}

Anthracyclines and their related compounds are among the best-characterized chemotherapeutic drugs leading to myocardial cell loss [5-8]. Myocyte damage has been attributed to a concentration-dependent increase of intracellular oxidative stress with a consecutive increase in cytosolic calcium, mitochondrial dysfunction (reviewed in [9]), and induction of myocyte apoptosis or necrosis [10 14]. Several studies have addressed the role of reactive oxygen species (ROS) as a mediator of anthracycline-induced damage to the heart. ROS not only lead to cell death, but also directly affect excitation-contraction coupling and 
Table 2 Risk factors for anthracycline and trastuzumab-associated cardiotoxicity

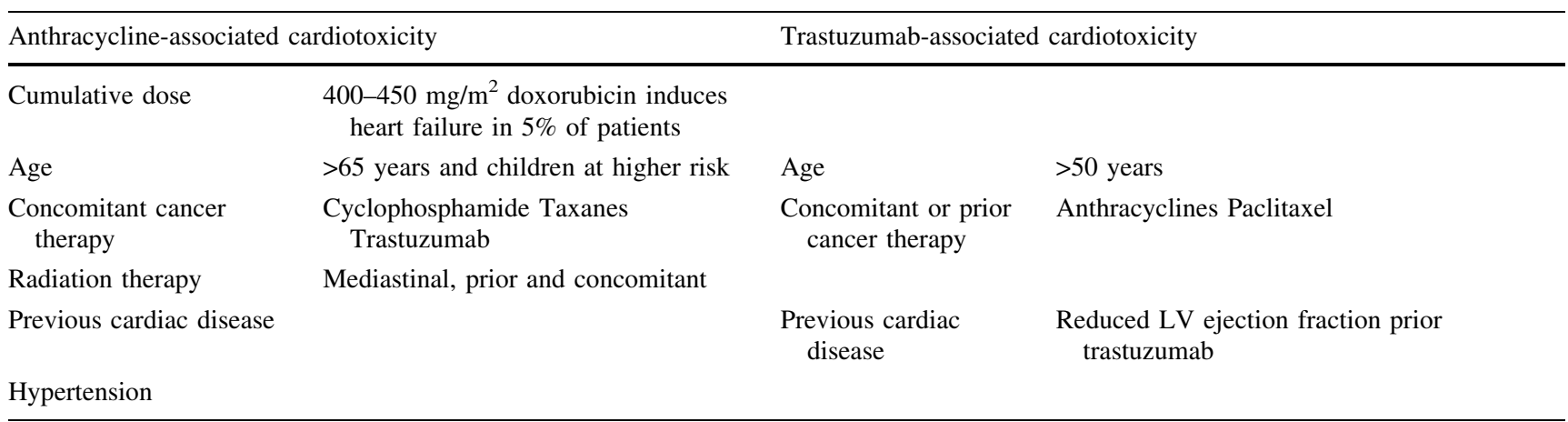

Table 3 Important cancer drugs with cardiac side effects

\begin{tabular}{|c|c|c|c|}
\hline Drug & Toxic dose range & Mechanism of cardiac toxicity & Type of cardiotoxicity \\
\hline $\begin{array}{l}\text { Anthracyclines } \\
\text { Doxorubicin } \\
\text { Daunorubicin } \\
\text { Epirubicin }\end{array}$ & $\begin{array}{l}>450 \mathrm{mg} / \mathrm{m}^{2} \text { total } \\
\quad \text { dose } \\
>900 \mathrm{mg} / \mathrm{m}^{2}\end{array}$ & $\begin{array}{l}\text { Free radical formation, DNA } \\
\text { intercalation }\end{array}$ & Contractile dysfunction arrhythmias \\
\hline $\begin{array}{l}\text { Antimetabolites } \\
\text { 5-Fluorouracil } \\
\text { Capecitabine }\end{array}$ & Conventional dose & Coronary artery vasospasm & Angina/myocardial infarction \\
\hline $\begin{array}{l}\text { Microtubule } \\
\text { targeting drugs }\end{array}$ & Conventional dose & $\begin{array}{l}\text { Microtubule stabilization, myofibrillar } \\
\text { disarray }\end{array}$ & $\begin{array}{l}\text { Bradycardia, cardiomyopathy in combination with } \\
\text { doxorubicin and trastuzumab }\end{array}$ \\
\hline $\begin{array}{l}\text { Taxanes } \\
\text { Vinca alkaloids }\end{array}$ & & Microtubule modulation & Myocardial infarction \\
\hline $\begin{array}{l}\text { Alkylating drugs } \\
\text { Cyclophosphamide }\end{array}$ & $\begin{array}{l}>100-120 \mathrm{mg} / \mathrm{kg} \text { over } \\
2 \text { days }\end{array}$ & Alkylating agent & Hemorrhagic myocarditis, cardiomyopathy \\
\hline $\begin{array}{l}\text { Anti-HER2 drugs } \\
\text { Trastuzumab } \\
\text { Lapatinib }\end{array}$ & Conventional dose & $\begin{array}{l}\text { Myofibrillar disarray } \\
\text { Combined Tyrosine Kinase Inhibitor }\end{array}$ & $\begin{array}{l}\text { Contractile dysfunction } \\
\text { Contractile dysfunction }\end{array}$ \\
\hline $\begin{array}{l}\text { BCR-ABL inhibitor } \\
\text { Imatinib }\end{array}$ & Conventional dose & $\begin{array}{l}\text { Inhibition of mitochondrial function, } \\
\text { oxidative stress }\end{array}$ & Contractile dysfunction? \\
\hline $\begin{array}{l}\text { Anti-angiogenic } \\
\text { Bevacizumab }\end{array}$ & Conventional dose & Antibody binding VEGF & Hypertension, myocardial infarction \\
\hline
\end{tabular}

calcium signaling in cardiomyocytes. Effects of ROS on Ltype calcium channels [15], sarcoplasmic reticulum ATPase [16], ryanodine receptors [17], and $\mathrm{Na}^{+} / \mathrm{Ca}^{2+}$ exchanger activity [18] have been reported. An increase in intracellular calcium after doxorubicin-treatment causes activation of the endogenous protease calpain-1, which specifically degrades the muscle protein titin in cultured adult rat ventricular cardiomyocytes [19]. This finding in cell culture models may explain one of the most prominent histological features of anthracycline-induced cardiomyopathy in patients, the loss of myofibrils. Recently, depletion of the transcription factor GATA4 by anthracyclines has been found, which could lead to apoptosis on the one hand and to downregulation of important cardiac genes on the other hand [20]. Counteracting, compensatory mechanisms can include induction and activation of endogenous antioxidant enzymes, such as glutathione peroxidase, metallothionein, cyclooxygenase- 2 and possibly nitric oxide and the survival factor neuregulin-1, which is released from microvascular endothelial cells under stress conditions [21-27]. The cumulative loss of myocardial cells and the exhaustion of compensatory mechanisms over time might explain the clinical observation that the cummulative dose is a strong predictor of anthracycline associated cardiac dysfunction.

\section{Cardiotoxicity of newer cancer therapeutics}

Significant side effects have been limiting cytotoxic chemotherapies since their introduction, but newly developed, 
so-called targeted therapies have recently opened up new possibilities in cancer therapy. Advances in the understanding of cancer biology at the molecular level have identified important signaling pathways, which are involved in cancer cell division, cell-cell interaction and the formation of new blood vessels in tumors. New biological therapeutics were then developed with the goal to specifically inhibit selected targets and to stop cancer cell proliferation and metastasis. These targeted therapies were thought to be more effective than traditional chemotherapeutic treatments and less harmful to non-cancerous cells. However, most of these new biological therapeutics per se are not cytotoxic and, therefore, need to be combined with traditional chemotherapeutics and radiation therapy. Furthermore, some of the targets inhibited by these new anti-cancer drugs appear also to be important for the maintenance of cellular homeostasis of normal tissue, in particular during exposure to cytotoxic chemotherapy.

Some of the new biological anti-cancer drugs associated with myocardial contractile dysfunction are trastuzumab, imatinib, and possibly bevacizumab ([28-30]; Table 3). Trastuzumab, an anti-HER2/erbB2 immunotherapeutic agent used in HER2-overexpressing breast cancer patients, has synergistic efficacy when used together with or after chemotherapeutic agents [31] and leads to tumor regression in metastatic disease and to an impressive reduction in the risk of recurrence when used as adjuvant therapy [32]. Unfortunately, the combination of trastuzumab with cytotoxic agents, in particular anthracyclines, bares a significant risk of cardiotoxicity $[28,33]$. Multivariate analysis for the development of cardiac dysfunction in the pivotal trastuzumab trials identified concomitant use of anthracyclines, prior anthracycline exposure, age $>50$ years, and prior cardiac disease as independent risk factors (Table 2). Many of these risk factors are similar to those for doxorubicin-induced cardiac dysfunction, suggesting that the erbB2/neuregulin system might modulate anthracycline-associated cardiac toxicity. Indeed, we have recently demonstrated that signaling via the erbB2 receptor can modulate doxorubicin-induced oxidative stress and myofibrillar structural damage in vitro $[19,34,35]$. However, in contrast to anthracycline-induced cardiomyopathy, trastuzumab-associated cardiac dysfunction appears to be mostly reversible and non-progressive [1,36]. Finally, combination therapy of trastuzumab with paclitaxel bares also an increased risk of cardiac contractile dysfunction [37], likely due to paclitaxel-induced myofibrillar structural damage secondary to attenuated basal phosphorylation of the Erk1/2 kinase and increased oxidative stress [35].

\section{Diagnosis of anti-cancer drug associated cardiotoxicity}

The tools for diagnosing anti-cancer drug associated cardiotoxicity and monitoring patients during chemotherapy include invasive and noninvasive techniques as well as laboratory investigations and are mostly only validated for anthracycline-induced cardiotoxicity and more recently for trastuzumab-associated cardiac dysfunction. It is important to differentiate between transient, reversible cardiac dysfunction, and non-reversible cardiac damage but frequently only the course over time allows differentiating between the two forms. The methods, which have a predictive value are endomyocardial biopsy and, less well documented, the release of serum markers such as troponin and natriuretic peptides (ANP, BNP), and heart rate variability.

The acute and subacute type of anthracycline-induced cardiotoxicity can occur immediately after treatment and is characterized by electrocardiographic changes (various tachycardias, including flattening of the T-wave, prolongation of the Q-T interval, and a decreased amplitude of the R-wave) and reversible depression of ventricular contractile function [7, 38]. Although dysrhythmias are recognized often in early doxorubicin cardiotoxicity, they are seldom a concern in late toxicity unless they occur as a component of severe heart failure. Right ventricular endomyocardial biopsy allows a correlation between myocardial structural abnormalities and contractile dysfunction and is the gold standard for the diagnosis of anthracyclineassociated cardiotoxicity [8]. Morphological changes described in the myocardium are initial vacuole formation and myofibrillar dropout and, at later stages, myocyte necrosis. However, the relatively high technical and logistical effort for this invasive procedure makes it less attractive for daily clinical routine. The release of troponin is associated with myocyte cell death and has also been shown to be a predictive factor for cardiac dysfunction, particularly in children when measured serially [39]. The increase of natriuretic peptides reflects an elevation of the (left or right) ventricular end diastolic pressure and has been shown to be of predictive value for anthracycline associated cardiac dysfunction [40, 41].

The most widely used technique for monitoring and diagnosing anti-cancer drug associated cardiac dysfunction is the noninvasive assessment of the left ventricular ejection fraction at rest by radionuclide angiography (MUGA) or echocardiography [42]. The left ventricular ejection fraction is the ratio of the blood volume in the heart at the end of systole to the volume at the end of diastole and is a function of myocardial contractility and of peripheral resistance. There is no clear advantage for using nuclear angiography or echocardiography, although it is generally believed that radionuclide angiography is a more objective measurement and echocardiography is more widely available and does not carry the disadvantage of exposure to radiation. Most experts agree that a drop in left ventricular ejection fraction of more than 10 points from baseline and to below $50 \%$ or below the institutional lower limit of 
normal indicates a significant drop in myocardial contractile function. However, it is important to realize that such a drop in left ventricular ejection fraction is a late event in the cancer drug-associated cardiotoxicity and therefore is not detectable until significant cardiac damage already occurred. The measurement of left ventricular contractile function by myocardial strain Doppler echocardiography might be a more sensitive measurement but needs validation and requires more sophisticated analysis than assessment of the ejection fraction. Otherwise, measurement of diastolic dysfunction and the contractile functional reserve also seem to be a more sensitive measure for cancer drugassociated cardiac toxicity. However, their use has been limited by a low specificity for diastolic dysfunction and the high technical efforts needed for the assessment of the contractile reserve.

\section{References}

1. Ewer, M. S., \& Lippman, S. M. (2005). Type II chemotherapyrelated cardiac dysfunction: time to recognize a new entity. Journal of Clinical Oncology, 23, 2900-2902.

2. Felker, G. M., Thompson, R. E., Hare, J. M., Hruban, R. H., Clemetson, D. E., Howard, D. L., Baughman, K. L., \& Kasper, E. K. (2000). Underlying causes and long-term survival in patients with initially unexplained cardiomyopathy. The New England Journal of Medicine, 342, 1077-1084.

3. Mann, D. L. (1999). Mechanisms and models in heart failure: A combinatorial approach. Circulation, 100, 999-1008.

4. Swain, S. M., Whaley, F. S., \& Ewer, M. S. (2003). Congestive heart failure in patients treated with doxorubicin: a retrospective analysis of three trials. Cancer, 97, 2869-2879.

5. Lipshultz, S. E., Lipsitz, S. R., Mone, S. M., Goorin, A. M., Sallan, S. E., Sanders, S. P., Orav, E. J., Gelber, R. D., \& Colan, S. D. (1995). Female sex and drug dose as risk factors for late cardiotoxic effects of doxorubicin therapy for childhood cancer. The New England Journal of Medicine, 332, 1738-1743.

6. Singal, P. K., \& Iliskovic, N. (1998). Doxorubicin-induced cardiomyopathy. The New England Journal of Medicine, 339, 900905.

7. Bristow, M. R., Mason, J. W., \& Daniels, J. R. (1978). Monitoring of anthracycline cardiotoxicity. Cancer Treatment Reports, 62, 1607-1608.

8. Mackay, B., Ewer, M. S., Carrasco, C. H., \& Benjamin, R. S. (1994). Assessment of anthracycline cardiomyopathy by endomyocardial biopsy. Ultrastructural Pathology, 18, 203-211.

9. Tokarska-Schlattner, M., Zaugg, M., Zuppinger, C., Wallimann, T., \& Schlattner, U. (2006). New insights into doxorubicin-induced cardiotoxicity: the critical role of cellular energetics. Journal of Molecular and Cellular Cardiology, 41, 389-405.

10. Hasinoff, B. B. (1998). Chemistry of dexrazoxane and analogues. Seminars in Oncology, 25, 3-9.

11. Gille, L., \& Nohl, H. (1997). Analyses of the molecular mechanism of adriamycin-induced cardiotoxicity. Free Radical Biology \& Medicine, 23, 775-782.

12. Doroshow, J. H. (1983). Effect of anthracycline antibiotics on oxygen radical formation in rat heart. Cancer Research, 43, 460472.

13. Maeda, A., Honda, M., Kuramochi, T., \& Takabatake, T. (1998). Doxorubicin cardiotoxicity: diastolic cardiac myocyte dysfunc- tion as a result of impaired calcium handling in isolated cardiac myocytes. Japanese Circulation Journal, 62, 505-511.

14. Kang, Y. J., Chen, Y., \& Epstein, P. N. (1996). Suppression of doxorubicin cardiotoxicity by overexpression of catalase in the heart of transgenic mice. The Journal of Biological Chemistry, 271, 12610-12616.

15. Campbell, D. L., Stamler, J. S., \& Strauss, H. C. (1996). Redox modulation of L-type calcium channels in ferret ventricular myocytes. Dual mechanism regulation by nitric oxide and Snitrosothiols. The Journal of General Physiology, 108, 277-293.

16. Arai, M., Tomaru, K., Takizawa, T., Sekiguchi, K., Yokoyama, T., Suzuki, T., \& Nagai, R. (1998). Sarcoplasmic reticulum genes are selectively down-regulated in cardiomyopathy produced by doxorubicin in rabbits. Journal of Molecular and Cellular Cardiology, 30, 243-254.

17. Dodd, D. A., Atkinson, J. B., Olson, R. D., Buck, S., Cusack, B. J., Fleischer, S., \& Boucek, R. J. Jr. (1993). Doxorubicin cardiomyopathy is associated with a decrease in calcium release channel of the sarcoplasmic reticulum in a chronic rabbit model. Journal of Clinical Investigation, 91, 1697-1705.

18. Goldhaber, J. I. (1996). Free radicals enhance $\mathrm{Na}+\mathrm{Ca} 2+$ exchange in ventricular myocytes. The American Journal of Physiology, 271, H823-833.

19. Lim, C. C., Zuppinger, C., Guo, X., Kuster, G. M., Helmes, M., Eppenberger, H. M., Suter, T. M., Liao, R., \& Sawyer, D. B. (2004). Anthracyclines induce calpain-dependent titin proteolysis and necrosis in cardiomyocytes. Journal of Biological Chemistry, 279, 8290-8299.

20. Aries, A., Paradis, P., Lefebvre, C., Schwartz, R. J., \& Nemer, M. (2004). Essential role of GATA-4 in cell survival and druginduced cardiotoxicity. Proceedings of the National Academy of Sciences of the United States of America, 101, 6975-6980.

21. Xiong, Y., Liu, X., Lee, C. P., Chua, B. H., \& Ho, Y. S. (2006). Attenuation of doxorubicin-induced contractile and mitochondrial dysfunction in mouse heart by cellular glutathione peroxidase. Free Radical Biology \& Medicine, 41, 46-55.

22. Adderley, S. R., \& Fitzgerald, D. J. (1999). Oxidative damage of cardiomyocytes is limited by extracellular regulated kinases $1 / 2$ mediated induction of cyclooxygenase-2. Journal of Biological Chemistry, 274, 5038-5046.

23. Maejima, Y., Adachi, S., Morikawa, K., Ito, H., \& Isobe, M. (2005). Nitric oxide inhibits myocardial apoptosis by preventing caspase-3 activity via S-nitrosylation. Journal of Molecular and Cellular Cardiology, 38, 163-174.

24. Sawyer, D. B., Zuppinger, C., Miller, T. A., Eppenberger, H. M., \& Suter, T. M. (2002). Modulation of anthracycline-induced myofibrillar disarray in rat ventricular myocytes by neuregulin1 beta and anti-erbB2: potential mechanism for trastuzumabinduced cardiotoxicity. Circulation, 105, 1551-1554.

25. Timolati, F., Ott, D., Pentassuglia, L., Giraud, M. N., Perriard, J. C., Suter, T. M., \& Zuppinger, C. (2006). Neuregulin-1 beta attenuates doxorubicin-induced alterations of excitationcontraction coupling and reduces oxidative stress in adult rat cardiomyocytes. Journal of Molecular and Cellular Cardiology, $41,845-854$.

26. Cote, G. M., Miller, T. A., Lebrasseur, N. K., Kuramochi, Y., \& Sawyer, D. B. (2005). Neuregulin-1alpha and beta isoform expression in cardiac microvascular endothelial cells and function in cardiac myocytes in vitro. Experimaental Cell Research, 311, 135-146.

27. Kang, Y. J., Chen, Y., Yu, A., Voss-McCowan, M., \& Epstein, P. N. (1997). Overexpression of metallothionein in the heart of transgenic mice suppresses doxorubicin cardiotoxicity. Journal of Clinical Investigation, 100, 1501-1506.

28. Slamon, D., Leyland-Jones, B., Shak, S., Fuchs, H., Paton, V., Bajamonde, A., Fleming, T., Eiermann, W., Wolter, J. M., 
Pegram, M., Baselga, J., \& Norton, L. (2001). Use of chemotherapy plus a monoclonal antibody against HER2 for metastatic breast cancer that overexpresses HER2. The New England Journal of Medicine, 344, 783-792.

29. Drimal, J., Zurova-Nedelcevova, J., Knezl, V., Sotnikova, R., \& Navarova, J. (2006). Cardiovascular toxicity of the first line cancer chemotherapeutic agents: doxorubicin, cyclophosphamide, streptozotocin and bevacizumab. Neuro Endocrinology Letters, 27(Suppl 2), 176-179.

30. Kerkela, R., Grazette, L., Yacobi, R., Iliescu, C., Patten, R., Beahm, C., Walters, B., Shevtsov, S., Pesant, S., Clubb, F. J., Rosenzweig, A., Salomon, R. N., Van Etten, R. A., Alroy, J., Durand, J. B., \& Force, T. (2006). Cardiotoxicity of the cancer therapeutic agent imatinib mesylate. Nature Medicine, 12, 908916.

31. Pegram, M., Hsu, S., Lewis, G., Pietras, R., Beryt, M., Sliwkowski, M., Coombs, D., Baly, D., Kabbinavar, F., \& Slamon, D. (1999). Inhibitory effects of combinations of HER-2/neu antibody and chemotherapeutic agents used for treatment of human breast cancers. Oncogene, 18, 2241-2251.

32. Piccart-Gebhart, M. J., Procter, M., Leyland-Jones, B., Goldhirsch, A., Untch, M., Smith, I., Gianni, L., Baselga, J., Bell, R., Jackisch, C., Cameron, D., Dowsett, M., Barrios, C. H., Steger, G., Huang, C. S., Andersson, M., Inbar, M., Lichinitser, M., Lang, I., Nitz, U., Iwata, H., Thomssen, C., Lohrisch, C., Suter, T. M., Ruschoff, J., Suto, T., Greatorex, V., Ward, C., Straehle, C., McFadden, E., Dolci, M. S., \& Gelber, R. D. (2005). Trastuzumab after adjuvant chemotherapy in HER2-positive breast cancer. The New England Journal of Medicine, 353, 1659-1672.

33. Strasser, F., Betticher, D. C., \& Suter, T. M. (2001). Trastuzumab and breast cancer. The New England Journal of Medicine, 345, 996.

34. Sawyer, D. B., Zuppinger, C., Miller, T. A., Eppenberger, H. M., \& Suter, T. M. (2002). Modulation of anthracycline-induced myofibrillar disarray in rat ventricular myocytes by neuregulin-1 beta and anti-erbB2: potential mechanism for trastuzumabinduced cardiotoxicity. Circulation, 105, 1551-1554.

35. Pentassuglia, L., Timolati, F., Seifriz, F., Abudukadier, K., Suter, T. M. \& Zuppinger, C. (2007). Inhibition of ErbB2/neuregulin signaling augments paclitaxel-induced cardiotoxicity in adult ventricular myocytes. Experimental Cell Research in press.

36. Ewer, M. S., Vooletich, M. T., Durand, J. B., Woods, M. L., Davis, J. R., Valero, V., \& Lenihan, D. J. (2005). Reversibility of trastuzumab-related cardiotoxicity: new insights based on clinical course and response to medical treatment. Journal of Clinical Oncology, 23, 7820-7826.

37. Tan-Chiu, E., Yothers, G., Romond, E., Geyer, C. E. Jr., Ewer, M., Keefe, D., Shannon, R. P., Swain, S. M., Brown, A., Fehrenbacher, L., Vogel, V. G., Seay, T. E., Rastogi, P., Mamounas, E. P., Wolmark, N., \& Bryant, J. (2005). Assessment of cardiac dysfunction in a randomized trial comparing doxorubicin and cyclophosphamide followed by paclitaxel, with or without trastuzumab as adjuvant therapy in node-positive, human epidermal growth factor receptor 2-overexpressing breast cancer: NSABP B-31. Journal of Clinical Oncology, 23, 7811-7819.

38. Dindogru, A., Barcos, M., Henderson, E. S., \& Wallace, H. J. Jr. (1978). Electrocardiographic changes following adriamycin treatment. Medical and Pediatric Oncology, 5, 65-71.

39. Lipshultz, S. E., Rifai, N., Sallan, S. E., Lipsitz, S. R., Dalton, V., Sacks, D. B., \& Ottlinger, M. E. (1997). Predictive value of cardiac troponin $\mathrm{T}$ in pediatric patients at risk for myocardial injury. Circulation, 96, 2641-2648.

40. Nousiainen, T., Jantunen, E., Vanninen, E., Remes, J., Vuolteenaho, O., \& Hartikainen, J. (1999). Natriuretic peptides as markers of cardiotoxicity during doxorubicin treatment for nonHodgkin's lymphoma. European Journal of Haematology, 62, 135-141.

41. Kouloubinis, A., Kaklamanis, L., Ziras, N., Sofroniadou, S., Makaritsis, K., Adamopoulos, S., Revela, I., Athanasiou, A., Mavroudis, D., \& Georgoulias, V. (2007). ProANP and NTproBNP levels to prospectively assess cardiac function in breast cancer patients treated with cardiotoxic chemotherapy. International Journal of Cardiology.

42. Shureiqi, I., Cantor, S. B., Lippman, S. M., Brenner, D. E., Chernew, M. E., \& Fendrick, A. M. (2002). Clinical and economic impact of multiple gated acquisition scan monitoring during anthracycline therapy. British Journal of Cancer, 86, 226232. 